\title{
A Imagem do sertanejo no Segundo Reinado: O sertão em Taunay e José do Patrocínio
}

The Image of the Sertanejo in the Second Kingdom: The Sertão in Taunay and José do Patrocínio

Rodolfo Araújo Santos ${ }^{* *}$

* Recebido em: 23.03.2017.

Aprovado em: 30.07.2017.

*** Mestrando em Sociologia pela UnB. Email:

rodolfogoias@gmail.com
Resumo: O presente artigo pretende explorar os mecanismos que teceram uma memória social do sertanejo - enquanto grupo social desconhecido e ligado a uma estrutura econômica rural e patriarcal. A centralidade é posta nos recursos discursivos e simbólicos envolvidos na materialização do sertanejo na memória nacional, entendendo-se o papel ativo da natureza como recurso simbólico para a consolidação do sertão.

Palavras-chave: sertão, natureza, seca, império, sertanejo, literatura.
Abstract: The present article has the intention to explore the mechanisms that had made a social memory of the sertanejo - as an unknown social group and connected with a rural and patriarchal economic structure. Focusing in the symbolic and discursive resources involved with the materialization of the sertanejo in the national memory. Understanding the active role of the nature as a symbolic resourse to the consolidation of the sertão.

Key words: sertão, nature, Império, drought, sertanejo, literature. 
O panorama que então subitamente se desdobra é realmente grandioso. Aos pés do expectador, vasta campina a que embelezaram magníficos acidentes; além, as grandes orlas da mata que acompanham as sinuosidades das belas águas do Aquidauana; ao longe, a extensa Serra de Maracujá, com os píncaros escalvados, refletindo os esplendores do sol, e coroando toda essa massa prodigiosa, azulada pela distância. Foi esse ponto, com razão, chamado Campo Belo (Lauiad) pelos guacurus. Parece apanágio dos povos civilizados o sentimento admirativo; pelo menos bem raro é, nos homens primitivos, a sua manifestação exterior. No entanto, as grandes linhas de um quadro majestoso da natureza conseguem, às vezes, vencer a feição material do selvagem, unindo ao autor da obra o rude expectador do maravilhoso. $\mathrm{O}$ primeiro guaiacuru que sobre esta região encantada deitou os olhos não pode conter a exclamação de surpresa; com voz gutural e cavernosa pronunciou a palavra Luaiad, que para sempre assinalou. (TAUNAY, 2006, p. 53)

Essa mesma paisagem seria cenário de uma luta permanente entre o homem e a natureza pela sobrevivência. Levando ao limite os valores morais e testando com indiferença a honra e a dignidade dos homens "civilizados" que ali se apresentaram.

Quanto ao plano primitivo, fora ele mais ou menos abandonado; quando muito ia servir de pretexto a que se infligissem as mais terríveis provações a uma pequena coluna expedicionária, quase perdida nos imensos e desertos sertões brasileiros. (TAUNAY, 2006, p.48)

Na mesma capital, em 1878, o ainda desconhecido jornalista José do Patrocínio embarca para o Estado do Ceará, tendo como finalidade cobrir in loco a recente seca que assolava, desde 1877, o sertão da região norte do país. Enviado como representante do jornal 
carioca, Gazeta de Notícias, seria responsável pela atualização das informações referentes à calamidade que ocorria no nordeste brasileiro. A quantidade de relatos e queixas enviadas ao Império e o singelo desenvolvimento das noções de cidadania por parte das elites locais fizeram com que o Estado se visse obrigado a se reorientar em relação aos motivos e às consequências desta seca ao povo brasileiro. Em outros termos, quais seriam os mecanismos utilizados pelo Império para solucionar de forma definitiva as mazelas geradas pela seca de 1877 e como o Estado assimilaria todas estas degradantes consequências?

O recém-jornalista possuía uma coluna intitulada "Viagem ao norte" que informava as condições da região, a situação política das cidades, a forma como os benefícios estavam sendo alocados, o tratamento dado aos moribundos e principalmente descrevia a situação física, moral e social dos retirantes.

José do Patrocínio, ao desembarcar nas principais cidades do norte brasileiro, encarou de perto as paradoxais características do clima da região nordeste. Em Fortaleza conheceu o fotógrafo Joaquim Antônio Corrêa, que registrou de forma austera os retirantes. Assim, num conjunto de textos lúdicos e ao mesmo tempo cortantes, somado às fotografias tiradas por Corrêa - imagem 1 -, a imprensa brasileira ajudou a moldar o imaginário Imperial sobre a seca, contribuindo para incorporar de forma definitiva o sertão no imaginário nacional. Em artigo publicano na Gazeta de Notícias em 20 de julho do ano de 1878, Patrocínio descreve sua chegada à capital cearense:
O paquete cortava as ondas, rápido como as várias cogitações que assaltavam, e em breve não vi no horizonte mais do que luz do farol na dimensão e colorido de uma pétala de rosa. Nada mais podia ver: abobadava-se por sobre mim um céu trevoso, acidentava-se em baixo mar em vagas sonoramente encapeladas, mas, numa espécie de anestesia, eu conservava-me ainda popa do paquete, com olhos fitos na esteira de espumas estendida pelo movimento das rodas na escuridão das águas. No azoinado imaginar do meu cérebro de entontecido, redemoinhava a bela cidade, ora parecendo fundir a vistosa casaria em colossal monumento, ora acentuando mais a sinuosidade do seu rio (...) Quando esta visão se desfazia, uma outra sucedia-lhe, semelhante a um assombro bíblico, a um enlevo de poeta . Era um estendal de nuvens negras, ladeadas de espectros. No meio do plano amarelecia alguma coisa semelhante a um pedaço de pão e por toda extensão, negramente nublada, crianças magras, mulheres desgrenhadas, homens disformemente inchados, velhas que mal podiam arrastar se, lutavam, corriam, pranteavam, assassinavam-se em demanda do mísero enguiço a fome devoradora de todos eles.

Uma voz veio-me arrancar do domínio da imaginação.

- Depois do belo o horrível - disse-me: - agora a treva e o enjoo, por fim os horrores da seca."

O belo e o horrível e o sublime e o grotesco tornam-se chaves interpretativas da imensidão do desconhecido Brasil 


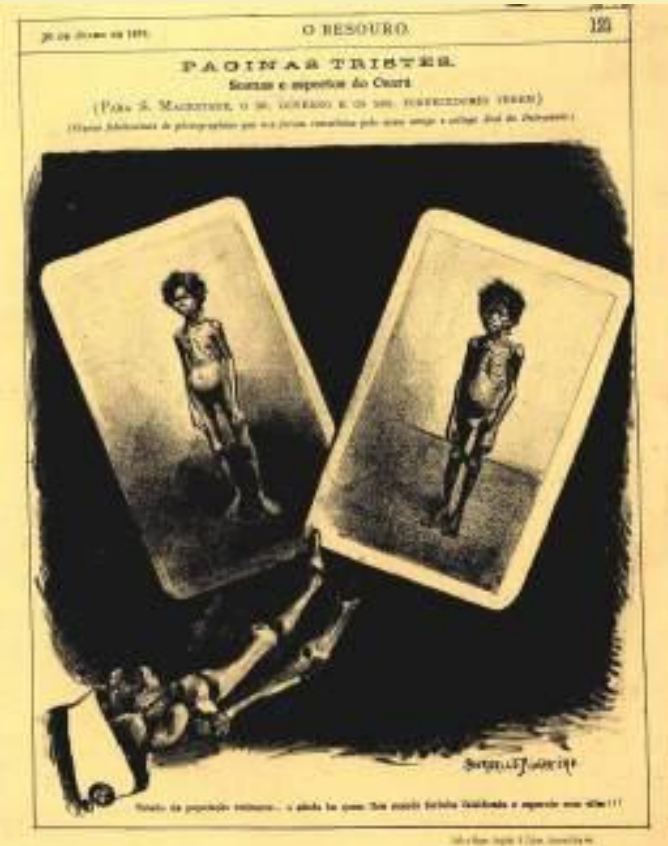

Imagem1: J.A. Correia. Seca de 1877-78. Ceará-Acervo FBN

$\langle\mathrm{http}: / /$ brasilianafotografica.bn.br/?p=1499>

As duas narrativas citadas acima incorporam duas regiões distintas do território brasileiro, contudo personificam a relação que o Império do Brasil tinha com seu interior. A figura do sertanejo aparece na medida em que este se torna um problema para o Estado. Definindo de forma provisória, entende-se sertão e sertanejo respectivamente como o território existente entre o litoral e as fronteiras do Brasil, e aquele que habita esta região.

As duas narrações representam - em momentos distintos e por causas distintas - a gradativa modernização do Brasil. Uma estrutura política minimamente burocratizada que ligava todas as regiões do Brasil (centralização política, a exclusividade tributária e o monopólio do uso da violência), uma cultura que gradativamente vai se solidificando e criando certa identidade entre os seus indivíduos (estrutura das emoções) e uma economia minimamente dinâmica que sustentasse uma demanda gradativa por modernização (estruturas materiais)

Entende-se que, no desenrolar dos anos, a figura do interiorano vai ganhando mais cores locais e mais especificidade. Contudo, irei trabalhar com a figura do sertanejo em termos genéricos, enquanto habitante dos territórios distantes das grandes capitais - situados entre o litoral e as fronteiras -, mas que se vinculam em termos "políticos" ao Estado brasileiro.

O presente artigo pretende explorar os mecanismos que teceram uma memória social do sertanejo - enquanto grupo social desconhecido e ligado a uma estrutura econômica rural e patriarcal -, centralizando nos recursos discursivos e simbólicos envolvidos na materialização do sertanejo na memória nacional e entendendo o papel ativo da natureza como recurso simbólico para a consolidação do sertão.

Usarei como fonte de análise e mediação a obra de Alfredo Taunay referente à Guerra do Paraguai e os artigos sobre a seca de 77, publicados por José do Patrocínio no jornal Gazeta de Notícias e seu romance Os Retirantes.

No último capítulo de sua obra sobre Mozart, o sociólogo Norbert Elias faz um esboço metodológico que aborda a trajetória do músico esquematizada em Atos e seguindo a estrutura de uma peça de teatro. É instrutivo perceber como arranjava seu quadro de pesquisa e encarava uma análise sociológica. O prelúdio do drama é 
dividido em duas partes, uma que resgata os problemas sociológicos, e a outra em que explora os problemas psicológicos. Assim, temos um quadro metodológico do indivíduo e sua produção cultural enquanto uma figuração - mutável e complexa - em estreita ligação com as estruturas sociais de longa duração e as estruturas de personalidade dos agentes. A produção cultural não é vista enquanto um ente pronto e acabado, mas como um processo dinâmico de formação do objeto em um contexto sócio-histórico, uma relação entre práticas sociais individuais e o conjunto das pessoas em si.

O presente artigo segue de perto Elias em dois momentos: a) reproduzir o conceito de figuração explorado pelo autor em suas obras magnas; e b) iniciar a investigação resgatando a primazia da contextualização, do aspecto coletivo, das estruturas historicamente reproduzidas ou das figurações na investigação da imagem do sertão. É necessário entender a dinâmica das estruturas sociais reproduzidas pela história e sua relação com as estruturas psicossociais e posteriormente situar as disposições mentais duráveis nesta rede de interações sociais.

\section{A sociologia processual de Norbert Elias}

Norbert Elias, durante sua profícua produção acadêmica, estudou a sociogênese dos processos de transformações sociais e a psicogênese dos processos de transformação psicossociais. Em outras palavras, quis compreender a relação estreita entre as transformações de estruturas sociais em longo prazo e as transformações na constituição das formas de sentir e pensar dos indivíduos.

Compreendia que as bases teóricas da sociologia estavam sustentadas numa falsa dicotomia, indivíduo/sociedade e subjetividade/objetividade, pois afirmava que a mesma dinâmica que produz mudanças estruturais na sociedade produz mudanças comportamentais no indivíduo, sendo impossível separar estas duas dimensões da realidade social na investigação sociológica. Qualquer teoria social que pressupunha esta díade estaria fadada a ser parcial e pouco frutífera teoricamente.

Elias, em sua obra Sociedade dos indivíduos, reconhece que só podemos entender o homem - indivíduo/autoconsciência - em termos das relações que são "outorgadas pelo destino e apenas em conexão com a estrutura da sociedade em que nasceu”. Em outros termos, o homem só se faz claro se contextualizado no horizonte da sociedade a qual pertence e que criou seus laços sociais (ELIAS, 1994; HEINICH, 2001)

Desenvolve-se disso a ideia de que os indivíduos possuem pouca força causal sobre os desdobramentos da sociedade e seu desenrolar histórico. Sendo assim, os indivíduos não influenciam os rumos da sociedade a qual pertencem, existem forças sociais e sentidos dados que escapam à vontade e a escolha dos sujeitos em ação. Em outros termos, o Rei talvez não tenha o papel principal na investigação social, mas as inter-relações, a estrutura social e a dinâmica da economia psíquica que possibilitam a existência de uma monarquia seja o caminho mais rico e produtivo sociologicamente. 
Contudo, é importante frisar que estes mesmos indivíduos em seu cotidiano são intencionalmente motivados e agem com objetivos claros, possuem um sentido subjetivo. Elias não recusa o papel proeminente do indivíduo, ele apenas contextualiza e relativiza a noção do individualismo no ocidente, apresentando uma alternativa teórica mais coadunada com a complexidade social e histórica.

Assim, Elias descarta a dicotomia indivíduo/sociedade e assume o conceito de figuração, pois este possui um sentido dinâmico, mutável e em permanente choque que expressa melhor a complexidade da realidade social e do que entendemos por indivíduo. Como bem define o historiador Roger Chartier, "Uma figuration (figuração) é uma formação social, cujas dimensões podem ser muito variáveis (...) estão ligados uns ao outros por um modo específico de dependências recíprocas e cuja reprodução supõe um equilíbrio móvel de tensões" (CHARTIER, 2001, p.12).

Em outros termos, uma figuração constitui uma comunidade interligada e interdependente, que mantém laços sociais em permanente choque, atrito este que não representa um potencial destrutivo, mas um choque que possibilita uma dinâmica na/da sociedade. É um contexto que permite uma relação tênue entre as margens de escolha dos sujeitos e as limitações sociais que o contexto pode oferecer - dependendo do tempo e do espaço - às aspirações dos indivíduos. Figuração é uma costura teórica que se propõe a corrigir a díade indivíduo/sociedade assumindo a interdependência entre os sujeitos, as relações entre os mesmos com estruturas de longa duração e a possibilidade de uma margem de autonomia do sujeito, sem priorizar uma esfera em detrimento de outra (ELIAS, 1994; HEINICH, 2001).

E embora, ao examinar do alto longos trechos da história, o observador possa notar, primeiramente, como é pequeno o poder individual das pessoas sobre a linha mestra do desenvolvimento e da mudança históricos, a pessoa que atua dentro do fluxo talvez tenha uma oportunidade melhor de ver quantas coisas podem depender de pessoas particulares em situações particulares, apesar da fixidez da direção geral. Somente as duas observações, longe de se contradizerem, resultam, quando adequadamente vinculadas, num quadro mais revelador e mais apropriado. (ELIAS, 1994, p. 47)

Dessa forma, Elias apresenta e sintetiza sua teoria. Para superar a díade entre indivíduo/sociedade - pois é impossível compreender os processos sociais nestes termos -, é necessário resgatar quadros sociais maiores e como estes configuram estados psicossociais específicos de uma figuração. Podemos ter indivíduos (e sua produção cultural) que se destacam do corpo social, mas isso não os torna notáveis ao ponto de serem classificados como apartados da sociedade, dado que a realidade do sujeito é engendrada em uma teia de relações que só foram possíveis naquela figuração social específica - e só se formaram e se mantiveram a partir de estruturas sociais assentadas em contextos históricos de extensa duração.

Elias afirma que as sociedades não são forças que possuem sentido intrínseco dado, teleologicamente -, nem com isso que os indivíduos são meros fantoches de forças sociais maiores. Sugere assim que contextos sociais são historicamente condicionados, contudo essa história se compõe de uma longa duração e que cada 
contexto de desenvolvimento social permite uma maior ou menor margem de ação individual e desenvolvimento psicossocial. Desse modo, cada sociedade permite ou não maior maleabilidade ao indivíduo e consequentemente maior percepção do funcionamento da realidade social.

(...) planos e ações, impulso emocionais e racionais de pessoas isoladas constantemente se entrelaçam de modo amistoso ou hostil. Esse tecido básico, resultante de muitos planos e ações isoladas, pode dar origem a mudanças e modelos que nenhuma pessoa isolada planejou ou criou. Dessa interdependência de pessoas surge uma nova ordem sui generis, uma ordem mais irresistível e mais forte do que a vontade e a razão das pessoas isoladas que a compõem. (Elias,1993, p.194)

$\mathrm{O}$ autor deixa claro que as reflexões em torno de uma antropologia filosófica - individualidade, liberdade, ontologia e subjetividade - só seriam possíveis em sociedades com características sociais específicas, com relações sociais específicas de Estados nacionais industrializados. Posto isso, só poderíamos pensar em um "eu" se a princípio formos capazes de dizer "nós". As condições sociais que permitiram esta questão sobre uma teoria do homem só foram viáveis dentro de sociedades com funções sociais desenvolvidas, densidade demográfica intensa, monopólio da força, da tributação e com um mercado financeiro dinâmico e intenso processo este ocorrido no ocidente. (ELIAS, 1994).

\section{O Império e suas contradições}

O período Imperial é marcado por três fases: a) período posterior à independência, definido por um governo sistematicamente centralizador; b) período regencial, em que, após a abdicação do trono por D.Pedro I, em 1831, o trono fica "vazio", porém governado por uma regência provisória aguardando a maioridade do jovem herdeiro, então com cinco anos; c) segundo reinado, período que vai do golpe da maioridade, em 1839, até a proclamação da República, em 1889, quando o país é governado por D. Pedro II.

No período regencial ocorrem sucessivas revoltas, todas elas vinculadas à insatisfação das províncias com a interferência do governo e a busca por maior autonomia econômica e independência política frente ao governo central. Este momento marca uma cisão na política brasileira: a formação de dois espectros políticos, os saquaremas e os luzias, que posteriormente se consolidam como conservadores e liberais - configurações políticas que orientariam as decisões econômicas, políticas e morais no período do Segundo Império.

Os conservadores defendiam um Estado mais centralizado e intervencionista, valores morais rígidos em relação à lógica patriarcal, defesa do legalismo jurídico (como forma de petrificar privilégios), uma unidade militar forte, uma administração coesa e prestativa para reforçar a unidade nacional. Em outros termos, a política de centralização seria um antídoto indispensável a uma divisão do país. Já os liberais, que não devem ser identificados com a defesa da democracia, buscavam a defesa pela liberdade de produzir, vender e comprar, o direito de representação política e a conservação da liberdade econômica de submeter o trabalho escravo ${ }^{1}$. Ambos os espectros são antidemocráticos e escravistas, porém mantêm 
1 O liberalismo brasileiro será dividido posteriormente em relação à questão servil, porém sempre se mostrou em sintonia com os interesses escravocratas. distinções políticas e econômicas que refletem as pequenas cisões existentes na elite econômica brasileira.

O Império é marcado pela centralização da economia na produção cafeeira tendo como mão-de-obra o trabalho escravo. Contudo, existia um mercado complexo, dinâmico e regionalmente diversificado opondo-se à visão generalista de uma monocultura escravocrata.

Temos a região norte com um forte desenvolvimento econômico, vinculado aos seringais e à extração da borracha drogas do sertão - levando a um intenso movimento de migração interna, intensificada principalmente com a seca de 77 . Com a guerra civil americana, aumenta o fluxo de exploração da floresta amazônica, gerando uma riqueza para a região, refletida na grandiosidade cultural e econômica das duas principais capitais do norte: Belém e Manaus.

O nordeste é caracterizado pela "Civilização do açúcar", expressão criada por Freyre, mas que descreve a riqueza e complexidade da região. É dividida em três áreas: o sertão, o agreste e a zona da mata, sendo a última responsável pela produção do açúcar - principal fonte econômica -, e as duas primeiras vinculadas à pecuária extensiva, produção algodoeira e a produção de alimentos para consumo da região - as atividades auxiliares

Muito embora a mão de obra escrava caracterizasse a economia açucareira no Brasil desde os seus primórdios até final do século XIX e os cativos sempre fossem preponderantemente como força de trabalho, o caráter da produção açucareira e suas exigências específicas criaram a necessidade de um grupo de assalariados no cerne do processo. Os trabalhadores do campo eram quase sempre escravos, em geral negros, preponderantemente africanos; os senhores de engenho eram inevitavelmente livres e brancos. Porém, nas funções intermediárias - administrativas, técnicas e artesanais - havia indivíduos livres, libertos e cativos, brancos pardos e negros (SCHWARTZ, 1988, p. 261).

A região de Minas Gerais não apenas se firmou na extração de ouro e diamante, mas na agropecuária, manufatureiros e de serviços. Sendo assim, o declínio da mineração não representou a regressão da região, pois esta manteve a centralidade na agropecuária e na produção de café na zona da mata mineira, sendo o estado com maior população no período, refletindo assim a rica economia da região.

Temos o Rio Grande do Sul com suas relações de trabalho particulares, intensidade migratória europeia, com a produção de alimentos para o consumo interno e as famosas charqueadas, responsáveis pela relação íntima entre a economia do sul e os outros países da região da prata. Este movimento este gerou uma economia dinâmica, população organizada, com forte identidade e atuante em termos políticos e econômicos.

Em termos gerais se delineou um panorama mais complexo da realidade brasileira, marcada pela produção extensiva de café para exportação e pelo trabalho escravo, porém com a presença de uma economia auxiliar que gerou modos de vida e hábitos distintos.

Em 1850 foram aprovadas duas leis que mostram as mudanças estruturais pelas quais passava o Brasil. Primeiro, a lei de 18 de setembro, conhecida como Lei da Terra, que tentou dar um status moderno à propriedade privada, refletindo a expansão sobre o território nacional e a necessidade do Estado de coordenar as 
2 Como mostra o autor de Capitalismo e Escravidão, Eric Williams, é possível - e, no caso, necessário - a convivência pacífica entre essas duas instituições econômicas - capitalismo e a escravidão. Porém, pretendo focar nas mudanças que ocorreram na reflexão política, moral e econômica sobre a existência da escravidão no mundo ocidental. relações territoriais com as novas dinâmicas de interesse. A Lei regulava que terras não registradas eram terras devolutas - terras do Estado. Assim, a posse da propriedade só se dava pela compra, excluindo a possibilidade de uma acesso democrático à terra no Brasil. Todo esse processo reforça a necessidade da adaptação das instituições políticas Imperiais à nova dinâmica econômica e social.

A segunda lei foi de quatro de setembro - Lei Eusébio de Queiroz -, que colocava fim ao tráfico de escravos e representava um processo contínuo em relação à lógica econômica brasileira e às novas necessidades morais e políticas da sociedade. Tratava-se de uma cultura escravocrata num mundo cada vez mais capitalista e liberal $^{2}$. Por um lado, temos a gradativa crise do escravismo e suas consequências econômicas estruturais; já por outro lado, temos a luta pela consolidação de um Império em progresso, garantindo nossa singularidade frente o artificial e imposto pelo estrangeiro. Uma pertinente busca pela nossa identidade nacional através de um Estado Nacional consolidado e este dependente de uma estrutura escravista que já se mostrava desgastada.

O século XIX brasileiro é marcado pela progressiva necessidade de uma revisão das bases de produção. O escravismo, enquanto modelo econômico, político e moral estava ruindo, gerando assim a necessidade de uma nova reorientação das bases de produção. $\mathrm{O}$ mercado se torna cada vez mais dinâmico e diversificado internamente, como foi apontado antes. Essa mudança foi gradativa e interligada a um desenvolvimento contínuo do Estado brasileiro. Temos a criação da Guarda nacional - milícia cidadã -, que representa um progresso na formação de um quadro militar necessário para a manutenção da ordem, mas retrógrado ao outorgar o uso legal da violência a forças patriarcais e tradicionais, como os grandes senhores de terra.

Após a traumática experiência das revoltas no período regencial, o Império resolve concentrar forças, consolidar uma política centrada na figura do imperador e voltada para o fortalecimento das fronteiras nacionais. Estava vinculado à manutenção das elites locais, desde que essas colaborassem para a manutenção das vastas terras e garantissem a soberania ao governo central. Temos uma relação orgânica entre a consolidação das instituições políticas, a organização da estrutura jurídica e a economia escravocrata - esta que se delonga a ruir devido a este vínculo estreito.

Usando de modelo teórico de Elias, compreende-se a figuração social da elite cultural brasileira ou da classe produtora de cultura. Temos um quadro estreito entre economia escravista, que mantém e sustenta toda uma lógica social. Um Estado que busca se modernizar e consolidar sua superioridade, autenticidade e singularidade. Porém, o mesmo é vinculado a uma economia escravista e a uma rede de relações de interesse que sustentam um programa político específico, sendo que este anula e inibe a participação de classes populares. Assim, são completamente inexistentes para o Estado enquanto agentes políticos.

Os grupos populares viviam numa rede de interdependência com os senhores locais, e os mesmos senhores se viam vinculados aos interesses do Império. Assim toda uma rede é conectada tendo como motor uma economia escravista e uma cultura que contribui 
para a manutenção desta ordem, comportando um discurso de autenticidade, nacionalidade e progresso que dependem de uma estrutura econômica que representava a própria impossibilidade de realização deste discurso.

\section{O Império e a Guerra do Paraguai}

Em decorrência do processo histórico de formação dos Estados Nacionais da região da Prata, em 1864, começam a se orquestrar pequenos atritos entre as recentes nações formadas: no Uruguai, a disputa entre blancos (ligados à Buenos Aires) e colorados (defensores da liberdade comercial e de navegação) pelo poder; na Argentina, o conflito entre os centralistas portenhos representados por Bartolomeu Mitre contra os federalistas de Entre Rios e Corrientes; já no Paraguai, o ambicioso e carismático líder Solano Lopez busca manter os interesses expansionistas e comerciais dos paraguaios. Enquanto isso, no Império brasileiro, desenvolvia-se um governo cada vez mais agressivo em relação à demarcação de suas fronteiras, na defesa dos interesses comerciais nacionais e na afirmação de sua superioridade moral e cultural.

No mesmo ano, Solano Lopez, num arriscado movimento, invade a Argentina e o território brasileiro, deflagrando a terrível e prolongada Guerra do Paraguai. Após as invasões é formado o Tratado da Tríplice Aliança - entre Uruguai, Argentina e Brasil para retirar Lopez do poder e restaurar as fronteiras. Entretanto, este conflito vai perdurar por mais cinco anos.
Uma das primeiras estratégias do Império seria atacar os paraguaios por duas frentes, uma vinda do sul, onde militares sairiam do Rio Grande do Sul e subiriam pelo rio Paraguai até a fortaleza de Humaitá. Uma segunda coluna militar desceria da capital da província do Mato Grasso, Cuiabá, enfrentando os paraguaios pelo norte. Possivelmente, essa combinação de duas frentes encerraria a guerra em poucos meses, não deixando ela se arrastar por longos e tortuosos cinco anos. Contudo, essa estratégia militar logo foi abandonada devido ao total desconhecimento por parte do Exército e do Estado brasileiro sobre a geografia da região de Mato Grosso e suas fronteiras.

Neste contexto é que se insere a obra de Taunay sobre a retirada da Laguna, descrita no início do artigo. $\mathrm{O}$ autor descende de uma ilustre família de franceses que vieram ao Brasil com incumbência de fundar a Academia Imperial de Belas Artes, que, com tom bonapartista, valorizava a racionalidade e o desenho como principais meios de expressão artística. A viagem para a guerra do Paraguai veio como meio de impor sua autonomia frente à família. Assim, como engenheiro da expedição pôde anotar diariamente suas impressões sobre o interior do país e sobre a guerra, acumulando material para sua produção literária e memorialística.

Vincula-se, assim, ao "entusiasmo romântico" e ao exercício da observação da natureza transformada em paisagem, o que define o papel da arte como "auxiliar das ciências naturais", pois só se pode conhecer viajando, e a natureza é o laboratório das experiências do viajante (...) Taunay fez-se um (d)escritor da natureza transformada em paisagem, compondo uma imagem descritiva da região que, juntamente com outras imagens construídas pela Monarquia brasileira, 
representaria a vontade consciente de definir a ideia de um Brasil homogêneo, mesmo que essa unidade figurasse como uma utopia nacional. (CASTRILLONMENDES, 2008, P.223)

O autor é comumente colocado como um nome menor na prosa romântica. Na maioria das vezes é acusado pelo excesso de cor local, minúcia na descrição dos costumes e por um "sentimento de paisagem" - predileção por descrições da natureza e suas exuberâncias. Porém, são essas as caraterísticas mais significativas para o presente trabalho, pois o autor expressa uma tendência de época. Tendência esta que buscava na natureza mais do que uma paisagem, mas uma fonte viva de identidade nacional, e assim via no interiorano as principais características do homem comum brasileiro, aquele responsável pela consolidação da nação. Encontramos no autor elementos que o situam numa transição entre o romantismo de cores idealizadas para o realismo com suas cores naturais. Dessa forma, descreve com traços patrióticos a diferença entre o Império e as repúblicas que o orbitavam:

O que, antes do mais, distinguia o Brasil império era a segura e valente coesão de todas as suas partes constitutivas [...] mantínhamos essa admirável unidade de vistas e ideais num vastíssimo, mas bem ponderado organismo nacional, animado por larga e generosa circulação vital, impulsionada de um centro único, mas, irradiando para todas as direções, sem deixar ponto algum a que não levasse ou procurasse levar o benefício de sua influição atenta e justiceira. (TAUNAY, 2006, p. 306)

Taunay narra as situações limites passadas pela sua expedição. Tanto as dificuldades enfrentadas para se chegar à região, quanto às desventuras sofridas no recuo. Num momento chave do translado encontraram aquele que seria a chave principal para a sobrevivência do grupo. O sertanista que serviu de guia, Jose Francisco Lopes. Homem rude nos modos, porém astuto na sabedoria acumulada sobre o sertão. Nascido em Minas Gerais, foi criado em contato com os agrestes brutos, adquirindo assim uma postura taciturna frente às dificuldades do interior - o que foi crucial para a superação dos problemas enfrentados pela expedição. De sua terra natal desbravou o Paraná até chegar às margens do rio Paraguai, dominando plenamente os mistérios destas planícies, mantendo os sentimentos nacionalistas e, ao seu modo, cuidando das fronteiras. Assim, Taunay descreve o sertanista Lopes:

Prodigiosamente sóbrio, viajava dias inteiros sem beber, trazendo à garupa da cavalgadura, pequeno saco de farinha de mandioca, amarrado ao pelego macio, que lhe forrara o selim. Jamais deixava o machado destinado a cortar palmito (...) tomara, em nome do Brasil, posse, ele só, de imensa floresta, no meio da qual chantara uma cruz, grosseiramente falquejada, onde esculpira a inscrição PII(Pedro Segundo), imponente madeira perdida no recesso dos desertos. Criava a iniciativa do sertanista domínios ao soberano. (TAUNAY, 2006, p.58)

Taunay não deixa de afirmar a presença de D.Perdo II na mente de seus súditos, imagem idealizada, mas que ajuda a entender a seguinte questão - com que povo pode-se firmar a constituição do Brasil enquanto nação? Nestes termos temos a primeira construção de quem seria este súdito e ao mesmo tempo representante do povo. Habitante dos longínquos e desconhecidos sertões brasileiros, o sertanejo representava esta apoteose do modelo econômico 
Com a consolidação da monarquia, após o turbulento período brasileiro, uma harmonia entre a natureza e o homem forte que a domina.

É preciso notar que Lopes possui uma rica fazenda nas fronteiras do Brasil. Mesmo sendo de Minas Gerais, não se inibiu em explorar e levar o Império aos seus limites. Pensar a dicotomia litoral/interior é entender como esse interiorano foi cada vez mais assimilado pela elite intelectual litorânea e em que situação este encontro foi possível.

Podemos afirmar que o processo foi em decorrência da modernização, pois esta possibilitou a estruturação de Estados soberanos que, ao se consolidarem, entraram irremediavelmente em conflito. Estados estes que possuíam uma ligação não apenas cultural e social, mas econômico com o antigo continente.

Temos um Império que juntou em um extremo de sua fronteira indivíduos pertencentes a diferentes regiões do desconhecido Brasil para resolver um conflito de caráter regional. Isso possível apenas porque já existia uma interconexão e dependência que vinculava as mais distantes regiões sobre a tutela de uma elite que se submetia a um Estado soberano, o Império brasileiro. Assim, aflora a existência de uma burocracia que, junto com as forças econômicas locais e a força militar, coordenou um vasto território. Afirma-se que o fenômeno da consolidação da identidade de uma nação e da inserção de sujeitos históricos aparentemente desconhecidos só existiu em decorrência dos desdobramentos da modernidade - fenômeno que se desenrolou, inclusive, sobre nações à margem dos grandes centros econômicos e culturais do mundo. regencial, iniciou-se um movimento de reestruturação das instituições científicas brasileiras. Temos um crescimento de cursos de direito, engenharia, ciências agrárias e a formação de institutos de pesquisa científica. Neste momento é fundado o Instituto Histórico Geográfico Brasileiro (IHGB), responsável pela pesquisa e organização da memória nacional, pela consolidação de uma identidade brasileira e organização do conhecimento referente à natureza.

A modernização brasileira que ocorre na segunda metade do século XIX não se limita a um processo urbano centrado na capital do país, mas a um processo que reorganiza o espaço brasileiro como um todo. Foi iniciada pelo Império com o desenvolvimento de cabos telegráficos e redes ferroviárias, a estruturação e o aperfeiçoamento do exército, a eficácia administrativa no manejo e gerenciamento do país a partir de um centro político. Estas características estavam vinculadas a uma economia prioritariamente escravocrata.

As inovações técnicas mais visíveis eram tributárias do ingresso de capital estrangeiro e da economia de expansão - de café, sobretudo, mas também de borracha e cacau -, nas construções de ferrovias, no aprimoramento da marinha mercante, nas reformas portuárias, e na instalação de serviços urbanos. (MURARI, 2009, p.25)

Contudo a intensidade da modernização era indiretamente proporcional aos canais de participação popular e efetiva mudança na estrutura econômica e de trabalho. Quanto mais moderna as estruturas políticas e culturais, mais à parte estava a população destas mudanças. Todos estes benefícios eram colhidos por grupos 
tradicionais da elite do Império. Uma inovação definida por Berman, ao descrever o caso russo, como "modernização do subdesenvolvimento", conceito proveitoso para a compreensão do caso brasileiro.

$\mathrm{O}$ modernismo russo fundamentou-se na imagem do descompasso entre a riqueza da experiência urbana e as condições incertas da vida econômica, entre o estímulo à subjetividade e o precário reconhecimento jurídicopolítico dos direitos do indivíduo, entre amplitude das possibilidades de comunicação no espaço da cidade e as restrições à liberdade de manifestação." (MURARI, 2009, p.27)

Devemos nos voltar para o futuro apostando na tecnologia como meio de atualizar o país ou voltar-nos para o passado, fabulando e repensando a formação colonial brasileira? É importar frisar que existiam duas narrativas que permeavam a mentalidade da elite letrada brasileira, uma que via no sertão fonte de nossa única e possível autenticidade, e outra que o atacava como fonte de toda barbárie e atraso da nação, sendo necessário domesticá-la.

O sentido atribuído à relação entre litoral e interior, considerando as versões que valorizaram negativamente os sertões, vistos como espaço da barbárie ou do atraso cultural, as que os idealizaram como lugar em que se desenvolveria a autentica nacionalidade, e as ambivalências em torno dessa representação geográfica/social. (LIMA, 1999, p.14).

Devemos notar que Taunay se inscreve no grupo que busca articular a descrição da natureza e a grandiosidade de seus habitantes como fonte de legitimidade para a construção de uma nação. Notificar um espaço como passível de se tornar uma paisagem é entendê-lo como fonte de construção de uma civilização. A natureza torna-se signo da consolidação da grandiosidade brasileira, e um povo capaz de domá-la e dominá-la seria forte o suficiente para compor uma nação.

A natureza vista como fonte de riqueza e matéria bruta a ser trabalhada, espaço a ser desbravado e povoado, mas também um sentido simbólico - a natureza como universo sensorial, manancial de vida e de identidade, força de resistência a ser submetida pela ação humana, paisagem que constituía o cenário da experiência, da memória social e da construção de uma imagem do Brasil, por si mesmo e para o mundo. (MURARI, 2009, p.20)

Sendo assim, o interiorano se apresenta ao imaginário brasileiro já introduzido numa malha de textos que existiam sobre a identidade nacional. As velhas referências à grandiosidade da natureza no Brasil consolidam um discurso que vê no habitante destas regiões valores nobres do homem rural, vinculado à lealdade e grandeza moral. O interiorano é um mestiço com atributos do branco, porém vivendo próximo a uma deslumbrante natureza que incorpora nele traços particulares e singulares do legítimo brasileiro.

\section{"Da seca do norte ao nordeste seco"}

Referências à seca na literatura de viajantes é uma constante na história colonial brasileira, contudo as referências ao fenômeno se tornam mais dramáticas e frequentes devido ao constante povoamento do sertão e das regiões agrestes, vinculado ao crescimento da atividade agropecuária. Sendo assim, a seca encontrava uma população despreparada para as consequências de uma longa estiagem. A pouca importância da produção econômica 
destas populações e seu significativo isolamento acabam por criar um significativo abismo entre as duas regiões - as comunidades do sertão em relação ao litoral - gerando diferenças sociais, econômicas e culturais

Contudo, a seca de 1877 deixa um impacto simbólico sobre o imaginário social da elite do Império. Devido à intensidade demográfica desenvolvida no decorrer dos anos, a seca atinge o sertão de tal maneira que o movimento de fuga gera um acúmulo de populações no entorno das grandes fazendas da zona da mata e nas grandes cidades do nordeste brasileiro. Este fator gera impacto demográfico, aumento de casos de desestruturação familiar, prostituição, epidemias e mendicância, forçando a necessidade de uma resposta eficaz do Estado e das elites políticas e econômicas locais.

Com a prolongação da seca, o evento que antes era visto como casual torna-se sistemático, deixando marcas permanentes na memória popular sobre o sertão e o sertanejo. A linguagem sensacionalista toma conta dos jornais do Império, e a seca passa a ser utilizada como recurso político para atacar adversários e partidos, sendo muitas vezes deixadas de lado as reivindicações dos retirantes e soluções eficazes para a seca.

Nesses anos, o grande assunto da elite política, em sua maioria sulista, foi manter em funcionamento as fazendas, especialmente as destinadas ao cultivo do café, sem o braço escravo. Os temas referentes à convivência com as secas - os açudes, poços, canal do rio são Francisco, entre outros - foram ignorados no Parlamento, nas deliberações governamentais e na imprensa: sobre o serão pairou a mais absoluta indiferença. (VILLA, 2000, p.39)

As soluções buscadas eram sempre superficiais e paliativas, evitando assim mudanças que pudessem alterar as estruturas econômicas e políticas da sociedade brasileira.

Sertão e litoral surgem no pensamento social brasileiro como imagens de grande força simbólica, que expressam os contrastes e, no limite, o antagonismo de distintas formas de organização social e cultural. (LIMA, 1999, p.22)

Assim, no ano de 1878 é enviado como correspondente do jornal Gazeta de Notícias, José do Patrocínio, que, como foi citado no início do artigo, contribuiu para a solidificação do imaginário sobre o sertanejo - interiorano - que neste momento é o retirante. Da figura heróica daquele que domina a dura natureza dos sertões, passa a esfacelado e empecilho nacional, exemplo de nosso atraso e de nossas limitações. Contudo, é importante frisar que o próprio Patrocínio publicou um artigo, antes da viagem para o Ceará, que reflete muito sobre como o sertanejo era interpretado pelas elites nacionais. O artigo intitulado "Sermão das lágrimas" aponta para a desestruturação e definhamento dos costumes tradicionais e dos valores morais - suporte da própria nacionalidade - em decorrência da grande seca de 77

Os retirantes, ao abandonarem sua terra natal, sua lógica cultural e seu meio ambiente acabam por deixar pra trás seus costumes mais nobres e dignificantes. Entram em choque dois mundos distintos, a comunidade rural e o mundo urbano, cada um 
com sua lógica e sua moral. A seca promove duas transformações: a) problemas nas estruturas sociais das sociedades rurais levando à mudança em massa para o espaço urbano; b) este por si gera um aviltamento moral próprio do mundo citadino.

São, portanto, registros que prenunciam como o século XIX recorta o mundo e como as imagens escritas e desenhadas por outros olhares se mesclam com a paisagem do interior brasileiro para construir outro mundo sobre aquele já existente e prenhe de significação. (CASTRILLON-MENDES, 2008)

A mentalidade agrária é responsável pela sustentação política e ideológica da Monarquia. A nova mentalidade social brasileira, que questiona e exige da Monarquia uma postura atuante politicamente, é de origem urbana.

Interessante demonstrar uma imagem bem difundida do sertanejo. Esta foi catalisada por José de Alencar em seu romance $O$ Sertanejo, que vincula a população interiorana a um tipo nacional específico: sertanejo como mestiço que incorpora a maneira dos brancos (valorização da família e da honra pessoal) e dos índios (lealdade e obediência). Expressava uma percepção típica da mentalidade senhorial - imagem rica do mundo rural, estável e próspera, uma ordem natural do homem do campo que eventualmente pode ser quebrada por algum distúrbio externo. Sendo assim, de uma imagem lúdica e harmoniosa do sertão, a partir da seca de 1877 o mesmo passa a ser um local hostil e inóspito, fonte dos piores valores, da degradação moral e social.
José de Alencar, em seu romance, reflete toda uma visão nostálgica sobre um passado de fartura e segurança dos sertões, nada mais que um reflexo da mentalidade senhoril. Assim, o artigo de Patrocínio dialoga com um discurso que já se orientava e existia, uma figuração que, como foi apontada acima, reflete um Estado burocrático centralizado, um domínio militar e uma estrutura econômica que sustentasse isso.

Um evento se consolida a partir de uma trama já existente; a possibilidade de uma nação é redimensionada com a presença dos retirantes e suas terríveis histórias de fome, mendicância, canibalismo e prostituição. Tal processo transforma uma seca que ocorre no norte para a imagem do nordeste seco, decadente e atrasado, comparado com a nova dinâmica urbana das capitais do sudeste e sul brasileiro. Esta catástrofe ocorre num momento cultural cujas ideias principais eram o modernismo, o liberalismo, o positivismo e o evolucionismo.

A imprensa forja um retrato permanente, a partir de imagens e textos não apenas sobre o interiorano, mas sobre as possibilidades de pensar a identidade nacional e o futuro do país.

Os artigos publicados por Patrocínio expressavam um deslumbre com a natureza, em sua exuberância. Contudo, o contato com o retirante, figura chave da interpretação do interiorano, acaba por denunciar os limites impostos pela natureza e pela história grupo social visto com tom lúdico passa a ser visto como decadente e potencialmente nocivo à sociedade.

Com Patrocínio, a instituição social da família é destruída pelas consequências da seca, consolidando uma imagem de sertão 
não mais como horizonte harmonioso e tradicional, mas território de miséria, degradação e naturalmente hostil. Da imagem de uma seca, como fenômeno casual, o nordeste torna-se uma região inóspita e permanentemente árida, um sertão indomável e miserável cuja única solução seria o auxílio do Estado e assimilação do mundo rural pelos centros urbanos e pela modernidade.

\section{Conclusão}

É importante compreender que os discursos e as imagens oriundas de relatos como da seca de 77 e da Guerra do Paraguai não encontram um terreno vazio de significados. José de Alencar, ao publicar $O$ Sertanejo, expressa um sentimento comum entre a intelectualidade brasileira da época, oriunda da elite rural letrada. Este imaginário catalisa uma necessidade de se pensar a identidade nacional numa sociedade cujo principal motor econômico é o trabalho escravo.

É importante pensar a construção da nacionalidade a partir da forma como o Estado assimila os excluídos, seja pela simples eliminação ou pela capacidade de reinterpretar simbolicamente os grupos sociais marginais - os indígenas, os negros, mestiços e os interioranos. Sendo assim, fica evidente no texto de Alencar que ele assimila o sertanejo/mestiço dentro da lógica patriarcal e escravocrata, vendo no interiorano o habitante das remotas e sublimes paisagens do Brasil - uma comunidade de auxiliares, apêndices necessários para a consolidação do sonho Imperial.
José do Patrocínio e Taunay dialogam com essa mesma mentalidade: o último vê no sertanejo Lopes um braço forte a serviço da nação e do Império; o primeiro vê nos retirantes a decadência de uma ordem rural frente aos empecilhos da natureza e a corruptível vida urbana.

Patrocínio sugere que o sertanejo, antes de qualquer coisa, é uma vítima de sua condição social, de seu habitat e de sua natureza. É um agente sem agência, sendo fruto de uma figuração econômica que se modernizava aos trancos, sem efetivamente dinamizar sua estrutura produtiva. O Brasil era um Estado-Nação que não precisava de sua gente para se consolidar, mas necessitava de sua miséria para existir materialmente. Consequentemente, foi necessário criar mecanismos políticos e discursivos para assimilar esse grupo. Imagens que revigoravam o Império, mas que ao mesmo tempo, representavam uma limitação para a devida modernização da sociedade brasileira.

\section{Referências}

ALVES, Elder Patrick Maia. A economia simbólica da cultura popular sertanejo-nordestina. 2009. 385 f. Tese (Doutorado em Sociologia)-Universidade de Brasília, Brasília, 2009.

BERMAN, Marshall. Tudo que é sólido desmancha no ar, Ed. Cia das Letras, 1990.

BOSI, Alfredo, A escravidão entre dois liberalismos. Estud. av. v.2 n.3 São Paulo set./dez. 1988. 
CARVALHO, José Murilo (Org.) - História do Brasil nação - A Construção nacional - 1830 - 1889, Ed. Objetiva, 2012.

CASTRILLON-MENDES, Olga Maria. Taunay viajante: uma contribuição para a historiografia literária brasileira. revista do IEB n 46 p. 217-240 fev 2008

CHARTIER. Roger in: "Prefácio", Sociedade de corte, Rio de Janeiro: Zahar, 2001

DORATIOTO, Francisco, O Conflito com o Paraguai - A grande guerra do Brasil, Ed. Ática. 1996.

ELIAS, Norbert. A Sociedade dos indivíduos. - Trad. Vera ribeiro. Rio de Janeiro: Jorge Zahar ed, 1994.

ELIAS, Norbert. Mozart, sociologia de um gênio. Trad. Sérgio Goes de Paula - Rio de Janeiro: Jorge Zahar Ed., 1995.

ELIAS, Norbert. . O processo Civilizador, Volume 1: uma história dos costumes 2.ed - Rio de Janeiro: Zahar, 2011.

ELIAS, Norbert. O processo Civilizador: formação do Estado e Civilizador. - Rio de Janiro: Zahar, 1993.2V.

ELIAS, Norbert. Os Estabelecidos e os Outsiders. Rio de Janeiro: Zahar, 2000

NEVES, Frederico de Castro. A miséria na literatura: José do Patrocínio e a seca de 1878 no Ceará. 13-11-2017< http://www.scielo.br/pdf/tem/v11n22/v11n22a05.pdf>

HEINICH, N. A Sociologia de Norbert Elias. EDUSC, 2001

HOLANDA, Sérgio Buarque. Do Império à República. Ed, Difusão Européia. 1971.
LIMA, Nísia Trindade. Um sertão chamado Brasil - Rio de Janeiro. Ed. Revan. 1999.

MAIA, João Marcelo Ehlert. A Terra como Invenção - Rio de Janeiro, Ed. Zahar, 2008.

MURARI, Luciana. Natureza e cultura no Brasil - São Paulo: Alameda, 2009.

PATROCINIO, José do. Os Retirantes - Editora Três, 1973.

SCHWARTZ, Lilian Moritz, Retrato em Branco e Negro, Ed. Companhia da Letras, 1988.

SCHWARTZ, Lilian Moritz (org) - Coleção História do Brasil Nação - Crise Colonial e Independência 1808-1839. Ed. Objetiva, 2015.

SCHWARTZ, Lilian Moritz (org) - Coleção História do Brasil Nação - Abertura para o mundo. 1889 - 1930, 2016.

TAUNAY, ALFREDO. A Retirada da Laguna - Edições do Senado Federal, 2011.

VILLA, Marco |Antonio. Vida e Morte no Sertão. Ed, Atica, 2000.

\section{Fontes}

Links para os artigos escritos por José do Patrocinio sob o título "Viagem ao Norte" publicados no jornal Gazeta de Notícias.

Coluna Folhetim, "Viagem ao Norte", Gazeta de Notícias, edição de $1^{\circ}$ de junho de 1878 .

Coluna Folhetim, "Viagem ao Norte”, Gazeta de Notícias, edição de 6 de junho de 1878 .

Coluna Folhetim, "Viagem ao Norte", Gazeta de Notícias, edição de 20 de julho de 1878 . 
Coluna Folhetim, "Viagem ao Norte", Gazeta de Notícias, edição de 23 de julho de 1878.

Coluna Folhetim, "Viagem ao Norte", Gazeta de Notícias, edição de 3 de agosto de 1878.

Coluna Folhetim, "Viagem ao Norte", Gazeta de Notícias, edição de 15 de agosto de 1878

Coluna Folhetim, "Viagem ao Norte", Gazeta de Notícias, edição de 22 de agosto de 1878 .

Coluna Folhetim, "Viagem ao Norte", Gazeta de Notícias, edição de 30 de agosto de 1878 .

Coluna Folhetim, "Viagem ao Norte", Gazeta de Notícias, edição de 7 de setembro de 1878 .

Coluna Folhetim, "Viagem ao Norte", Gazeta de Notícias, edição de

12 de setembro de 1878 . 